\title{
Bioethics and large-scale biobanking: individualistic ethics and collective projects*
}

\author{
GARRATH WILLIAMS
}

\begin{abstract}
Like most bioethical discussion, examination of human biobanks has been largely framed in terms of research subjects' rights, principally informed consent, with some gestures toward public benefits. However, informed consent is for the competent, rights-bearing individual: focussing on the individual, it thus neglects social, economic and even political matters; focussing on the competent rights-bearer, it does not serve situations where consent is plainly inappropriate (eg, the young child) or where coercion can obviously be justified (the criminal).
\end{abstract}

Using the British experience of large-scale biobanking, I argue that the focus on consenting individuals distorts our ways of thinking about biobanks and has serious practical ramifications. This becomes clear if we contrast the case of adult biobanks intended for medical research with two other forms of biobanking. Thus child cohort studies - vital for sound scientific investigation of the interplay of genetics and environment in health - have been very badly funded next to adult studies. On the other hand, forensic databases have attracted massive investment, but little debate partly owing to a sense that here, at least, is a case where consent is not relevant.

Contrasting these central types of biobanking, I will suggest that there are powerful factors at work in limiting 'ethics' to individual rights. Projects of this size should direct our attention to more overtly political questions concerning priority setting and organisation of medical research.

\section{Introduction}

In this paper I wish to cast a critical eye at the way in which we - meaning both bioethicists and practitioners - frame ethical and bioethical discussion. A slow swell of protest has been gathering, from many directions, against the idea that protection of individual rights should be the central focus of bioethical concern. ${ }^{1}$ Nonetheless, standard assumptions, and powerful institutions, continue to equate (bio)ethics with the protection of individual patients or research subjects - protections most often framed in terms of confidentiality and informed consent. ${ }^{2}$

My discussion will be particularly concerned with large-scale biobanks, and the difficulties that we have experienced in deciding - or discovering - the principles by which they might be regulated and governed. Part of our difficulty has come from the fact that biobanking is in fact highly variegated in form: many different sorts of biobank exist, but those that have attracted the most attention are as yet more intent than reality. Especially in the UK, but also beyond, debate has centred around two examples of large-scale biobanking for medical research which are either - in the case of UK Biobank - still being planned, or - the Icelandic database - only partly realised. One difficulty, then, is that we have spoken more about intended projects - 
and not exploited the experience we do have with biobanking. The second is that public and policy discourse, and to some extent bioethical reflection, has taken its orientation from now conventional moral categories of medical research ethics. So we have heard a great deal more about principles focussing on individual rights and protections - informed consent and confidentiality - than other principles or ethical frameworks. This is surely very odd, given the necessarily collective nature of these projects. $^{3}$

This suggests two routes toward greater clarity about the legitimating principles for human biobanking. First, that we ask whether our dominant focus on individual rights, so clearly ill-suited to reflecting on large-scale collaborative research, might serve other purposes beyond the protection of individual rights. Second, that we give attention to the already existing, and in some cases highly successful, examples of biobanking, and how far individual rights provide a framework for ethical reflection on these.

I begin by examining how it may be that we have come to identify ethics with a focus on individual rights, above all informed consent, and the different purposes and interests this focus may serve. I then describe some notable examples of large-scale biobanks, and examine how a focus on individual rights hinders us in appreciating the ethical issues that they raise. I conclude with the contention that, although some organised interests may be motivated to separate (bio)ethics from questions of undoubted political significance, a concern with ethics must point us in exactly the opposite direction. To focus on individual rights may actually undermine individual rights and interests, in ways that benefit some organised interests, because important social, political and scientific questions are left out of consideration. ${ }^{4}$

\section{Individual rights and informed consent}

The main planks of medical research ethics after the second world war are wellknown, first and foremost in the form of the World Medical Association's Declaration of Helsinki (1962). Against the horrifying abuses of individuals that were perpetrated in Nazi Germany and Japan, and against increasing awareness of serious on-going abuses within democracies such as the USA or even Sweden, two ideas were made central to medical research ethics. The first was the free and voluntary consent of the individual research subject. This coincided, of course, with Western societies' increasing emphasis upon the informed consent of patients to any medical interventions they might undergo. The second measure was ethical review of research trials via 'research ethics committees' or 'institutional review boards.' Of course, it was not only that 'experiments' were done that no-one in their right mind would consent to, but - and this fact gets forgotten when we focus on informed consent alone - the research (or so-called research) should never have been conceived of in the first place. To these two key planks of research ethics we should also add confidentiality, carried over from conventional medical ethics. 
The individual rights, to confidentiality but above all to informed consent, have come to dominate ethical thought about medical research. This may be an unfair generalisation so far as academic bioethical reflection is concerned, long since advanced beyond its 'four principles' stages. But so far as a generalisation can be fair, I suggest this reasonably applies to the teaching of bioethics, to common perceptions of (bio)ethics, and to the avowedly 'ethical' components of policy thinking. Simply and crudely: when most people, and most organisations, think of ethics they think of ethical safeguards for individuals. The background assumption is that research is a good, if not a good in itself; and therefore all that ethics need do is ensure that the rights of participants are respected: consent and confidentiality. While research ethics committees continue to scrutinise research proposals from the point of view of scientific soundness and not just individual rights, we still find a natural and unfortunate division between 'good science' and 'good conduct.' More than this, these standard mechanisms to protect rights and to ensure that research is wellconceived do not answer as to which research is pursued, which avenues ignored, and how research is organised. Not all research, after all, is equally desirable.

It is a difficult question, why we should have come to think that the ethics of medical research can be decided in terms of safeguards for individual rights, above all informed consent. I would like to suggest that a diverse range of factors has been at work. Some of these undoubtedly reflect good and valid reasons for insisting on the importance of consent to medical research (although my own view is that consent should not be necessary for every sort of research ${ }^{5}$ ). But there are other factors at work here, that suggest that our focus on consent is a little too convenient: that it may fit too neatly with some common habits of Western thought, that such a focus may in fact serve organised interests which can work against the public good and even the good of individual research subjects. We can view informed consent as a powerful case study of how any principle - however valid it may be - is always more complicated and ambivalent in its practice than we might like to think.

The difficulty of this question - why we should so often focus on informed consent is only enhanced when we remember some obvious and well-known difficulties that attend it. Allow me to mention only a few. ${ }^{6}$

- As study upon study has shown, the 'informed' aspect of informed consent proves to be rather fleeting. People persistently ignore, forget, misunderstand the information that researchers provide them with; quite often they forget that they have consented to a research project at all. There is the further question as to whether the promises and information that potential research subjects are given are actually accurate, which points us to the need for institutional oversight of this, and other, aspects of how any research project is conducted. It seems, indeed, that many research ethics committees have come to see their most substantive 'ethical' task as ensuring the accuracy of informed consent forms. 
- Informed consent is irrelevant to many groups of (potential) research subjects. It is impossible with infants and problematic with older children. It is also pretty much useless for the retarded, the senile, the demented and for some types of mental illness. ${ }^{7}$ Indeed, as evidence for my claim that informed consent tends to orient our thinking and practice, sometimes harmfully, we might recall the well-known problem of non-research that arises here. The effects of many drugs on children are simply not researched or documented, vastly increasing the risk when they are thought necessary to treat a child. Instead of organised research, then, we have a plethora of unorganised, unreported and unsynthesised experiments on people who are incompetent to consent.

- When we focus upon individual consent to research, we also neglect the importance of statutory research, that poses few risks to individuals but is essential to the running and improvement of collective health provision. Examples include: audits of medical practitioners, teams and organisations; monitoring for cost-effectiveness; research concerning public health and epidemiology; follow-up of medical interventions for side-effects and efficacy; monitoring of notifiable diseases; and the keeping of disease registers. These have usually not been subject to informed consent and their value would be undermined if they were, in terms of not only incompleteness but also probable selectivity in opting out. ${ }^{8}$ One way such research has been defended from the requirement of informed consent is by the anonymisation of subjects' samples and/or information; but this is not always possible or desirable.

- Informed consent is about individuals, and one of its purposes is to empower individuals against organised and expert researchers. However, it can actually obscure this power relationship. Requiring consent will not, by itself, alter the fact that uncoordinated individuals are always subject to the power of organised groups or institutions. This fact may not be problematic so long as we can reasonably take the benefits and organisation of research for granted. But for many reasons this is not something we should do. One important advance in the organisation of medical research occurred with the advent of HIV/AIDS. As we know, this disease was very badly researched to begin with, largely because of prejudice against the groups who were worst affected. One response was political organisation among some of those groups, to lobby for and even fund the necessary research. As became clear, not all the institutions involved in medical research are operating in the public interest; indeed, we should be well aware that no organisation can be trusted reliably to serve that interest without active public scrutiny.

All these well-known difficulties only sharpen the question: why should informed consent have become so definitive of medical and research ethics - not just in (philosophical) bioethics but above all in how ethics is understood by practitioners, policy-makers and their institutions?

In the philosophical context, consent has a natural fit with certain framing assumption of much ethical theory. Key among these is our customary focus on individual duties, 
individual rights, and respect for the choosing subject via the elusive, multivalent notion of autonomy. This relates to a tendency to focus on the competent, rightsbearing adult, wrongly seen as independent rather than interdependent. Furthermore, it is connected with a view of ethics that is separated from politics by a focus on individual decision-making - and exhibits a corresponding tendency to ignore how contexts of choice are formed, especially how institutions structure, enable and disable our choices. That is to say, some framing assumptions of philosophical ethics fit rather neatly - too neatly - with a focus on consent and other individual rights such as confidentiality. To put the point mildly, this makes it more difficult to frame discussion of issues that arise in collective action and decision-making - not least, in my context here, how medical research is organised and prioritised. However - this point is essentially to do with academic theorising, and has less explanatory power when it comes to practitioners' and policy discourse, not to mention that of lay people.

So far as lay people are concerned: None of my contentions here are meant to dispute how important are the protections and guarantees that informed consent provides to the subject of both treatment and research. The openness and choice signalled by informed consent procedures provide some protection for the subject's basic interests, and perhaps some opportunity to choose in the light of h/er own values. For parents, proxy consent provides a means to protect their child(ren) in the face of organisations that are not always trusted. The provision of information makes for openness, which is at least a precondition in ensuring fairness as well as protection of interests.

Some have argued that there is more to the story that this, and here we enter more ambiguous territory. One can see the practical emphasis on informed consent as fitting with a certain sort of self-conception. Investigation of what research subjects say and of what people who refuse to participate in research also say - suggests that informed consent supports an image of the "responsible subject.' ${ }^{9}$ That is, it enables people to see themselves as moral and responsible, choosing in the light of a moral imperative to participate in research. This is true even of those who refuse to participate: it is only that they find that possible risks weigh more heavily than the duty to assist research. In short, informed consent fits well with our ideas of what it is to be a responsible person - and who does not want to see $\mathrm{h} /$ erself as responsible?

This suggests that informed consent is serving, not the interests, but rather the selfimage of actual and potential research subjects. In itself, this may not sound particularly sinister. Protecting autonomy is protecting the right to choose in the light of one's values; and we have good reason to hope that people will number social responsibility amongst those values. If mechanisms of informed consent encourage this, then this is only a sign that our 'autonomy' is necessarily limited by the institutions in which we act and think - and rightly so, insofar as those institutions are just. 
This raises the question, of course, as to how just those institutions and their divisions of responsibility may be. Part of seeing oneself as responsible is accepting responsibility; and it may be that subjects of research are finding themselves accepting more responsibility than they ought. Many have noticed that informed consent procedures can involve an imposition of responsibility upon the subject, as co-decider, co-responsible for the project - someone who becomes 'concerned' in both senses, participating and anxious. Neo-Foucauldians such as Nikolas Rose have analysed modern Western societies in terms of 'responsibilisation.' Thus Rose claims, "individuals are not merely "free to choose," but obliged to be free, to understand and enact their lives in terms of choice. ${ }^{10}$ As a simple example, we might notice how many Western governments have preferred to target health interventions at individuals, rather than regulating the activities of commercial organisations. In the UK, childhood obesity has become a source of great concern, not to say moral panic. Thus far the response has been to emphasise parental responsibilities, and not (for example) to regulate the marketing of energy-dense foods by private enterprise.

In the context of genetics, an emphasis on individual responsibility has often been seen as a guarantee against the bad old eugenics. This has been very clear in the case of genetic counselling, for instance, in advising couples concerning the possible transmission of genetic disorders to any children they may have. The professional ethos of genetic counselling has centred on non-directiveness - a purported refusal to impose medical or state values upon the subject (in direct contrast not only to eugenics but also to the conventional value-laden-ness of medical care). ${ }^{11}$ But this distancing of the state - or rather, of health care practitioners who may be funded by the state - from individual choice has a potentially invidious aspect. It can be, indeed sometimes is, experienced as a handing-over of responsibility to the parents, constituting a refusal to help, to share responsibility for what can be immensely difficult decisions. $^{12}$

Returning to the context of medical research, this immediately suggests one reason why many subjects show so little recall of information about the project, and indeed may show very little interest in even "reading the form." What you don't know about can't be an object of your responsibility - or so we commonly tell ourselves. Not knowing can operate as a way of refusing a (dimly perceived) imposition of responsibility.

Consent procedures not only impose responsibility, for better or for worse. They can and do impose risks and costs on subjects. ${ }^{13}$ Informed consent procedures usually make clear that research subjects will not share in any profits or gains that stem from the research. Whatever its motivation, this clarification effectively functions as a renunciation of any possible entitlement to a share in profits or benefits. Thus informed consent forms become a contract clarifying future rights - or lack thereof. Sometimes consent forms will even disavow the researcher's liability should certain risks to the subject materialise - a provision that is certainly against the subject's interest and unquestionably to the benefit of the researcher's host institution. In either case, as one writer puts it, 'the consent becomes a waiver" ${ }^{14}$ - with regard to future risks to the subject, and future benefits to the researching institution. 
These darker aspects of informed consent are increasingly well-recognised, in the bioethical literature at least. Another problem is simpler, cruder and larger than all of the above. A focus on informed consent is also highly convenient for researchers and their institutions, and above all commercial enterprises. The reason is simple: insofar as individual rights delimit the domain of ethics, they shield other substantive issues from critical scrutiny. Not the least of these is the most important factor distorting priorities for medical research in the world today: the transnational pharmaceutical industry, operating in a context of gross global injustice and often in the context of inadequate or ill-conceived national health care frameworks. Pursuing a pill for every lucrative ill, this is an industry more concerned with marketing than research, more concerned with markets than needs, more concerned to market treatments than to prevent ill-health. The industry naturally promotes a reductive, individualistic and remedial approach to health, one that governments, researchers and health organisations have too often fallen in with. In the face of this enormous problem, informed consent, or other individual rights, are no answer at all - worse, such a focus constitutes an obstacle to perceiving the problem at all. Too often, it seems that to talk about such large and overwhelming factors is to stop talking ethics and to start talking something less respectable - that is, politics, something which (it may be implied) neither researchers or bioethicists should concern themselves with.

A second problem is related. If ethics is about consent or confidentiality, then ethics is no longer concerned with the scientific validity of research, gauging the likely benefits of research, and establishing priorities among well-grounded research possibilities. Evidently research ethics committees play an important role in addressing such issues at the micro level. Apart from the signal fact that this still leaves the macro level unaddressed, there remains the problem that 'science' and 'ethics' can too easily come apart. If such committees see their ethical task as protecting individual rights, and their scientific task as scrutinising the validity and workability of proposals, then at least two results ensue. The fact that scientific validity is a moral demand tends to drop from sight: yet validity matters so much because we want effective health interventions. Second, the extent to which a research proposal is worthwhile comes back to the narrower question of whether it should be able to properly investigate its leading hypothesis. The narrowing of ethics to individual rights can thus operate to support technocracy, ${ }^{15}$ distancing assessment and decision-making from the perspectives and concerns of non-experts, and leaving 'ethics' unable to challenge commercialism or other distorting factors in prioritysetting for medical research. The questions of whose health and whose interests will be served by research are too rarely asked, and need not be answered.

In short, while there are certainly good reasons for valuing informed consent, there are also several bad reasons why we may be led to over-emphasise it - reasons that have nothing to do with protecting research subjects and which divert our attention from the plain collective duty to choose our research priorities wisely. 


\section{Biobanking as a case study}

I turn now to the case of large-scale biobanking. Biobanking involves the storage of (i) tissue samples and/or genetic information and (ii) personal information, such as health care data (disease histories, treatments received), lifestyle information (nutrition, exercise, wealth, family background) and sometimes genealogy, or certain other sorts of identifying data.

Biobanking is not a new phenomenon, but it has taken on a much greater significance with the emergence of research into genetics and the first practical applications of genetic knowledge. In fact, two of the most important applications of genetic knowledge have not been medical at all. As we know, we are still a very long way from decoding all but the most simple health information from a person's genetic make-up (that is, chromosomal abnormalities and single gene disorders). What we can do is to use genetic samples to identify individuals and to identify basic genealogical linkages. At present, then, the most significant uses of genetic information are forensic investigation and paternity (or maternity) testing. Biobanking can then take two main forms: either to exploit these existing abilities, or as a basis for research to increase our understanding of the human genome and how its tiny variations between individuals might affect our bodily make-up and our health.

Exploiting existing abilities, and correspondingly the most well-established of biobanks, are forensic biobanks. The UK's National DNA Database is the largest in the world, with genetic profiles from just over three million people ${ }^{16}-$ it has doubled in size since 2002 and we are told to expect a similar rate of increase for the foreseeable future. When DNA samples can be extracted from traces left at crime scenes, they can be processed and the resulting 'profile' compared with the millions on record. Sometimes a match will occur, which can be invaluable in linking different crimes or in identifying a culprit. Sometimes too a sample can be taken from a suspect and shown not to match DNA that can be reliably identified with the crime: so suspects can be shown to be innocent, not just guilty. The UK also has a large database for paternity testing, so that financial responsibilities for childcare can be allocated to the biological father, where partnerships have broken up. This is much smaller, and I will leave it aside here.

Of course, these sorts of biobank can also be used for various forms of research, however unclear the ethics of this might be. The greatest interest here has naturally been in deriving phenotypic information from a genetic sample, so as to aid identification of the person who has left traces at a crime scene - thus information about quantitative traits such as height; hair, skin and eye colour; or even facial characteristics. This research is still in its infancy, and other possible discoveries such as correlations between genetic make-up and behavioural traits (the 'criminal gene'?) are, for the moment, no more than science-fiction. 
The other forms of biobanking are principally concerned to increase our knowledge of how genetic variation influences body and health. One older form of biobanking, which I will not be concerned with here, is simply the storage of human tissues from people suffering from particular disorders. This has been going on for a long time, because there are many properties of tissues that are more immediately and obviously relevant to health than DNA. These banks tend to be relatively small, spread out across the health service and private companies, and are often not documented, many being built up by individual researchers in the course of their careers. These diseasespecific banks, apart from not being principally concerned with genetic research, are also close to conventional medical research in that it is samples and data from the unwell that are used. Often the data will be gathered post-mortem, which also means it can effectively be anonymised and does not raise so many issues of individual rights. (However, it can raise profound concerns about parental rights, as we saw in the UK's Alder Hey scandal, when organs from dead children were taken for research without parents' understanding.)

Neither the involvement of the unwell, nor even the deceased, apply to the two forms of biobanking which I would like to consider alongside the forensic case. In these cases, samples and information are taken from many people, most of whom are not suffering any particular disease or disorder. The information, and perhaps samples too, are taken on an on-going basis.

The examples that have attracted the most attention, perhaps because of their sheer scale and novelty, are the large-scale biobanks for adult medical research. The most well-known, and the furthest along the path to being realised, is the Icelandic genetic database. This is a complicated arrangement, which was originally supposed to be made up of three different databases, and has several distinctive features:

- Samples and genetic information, and genealogical information are being entered onto two separate but linked databases. Originally a further database of health care data was conceived, the Health Sector Database, but it now appears unlikely that this will be created.

- The whole population is included in the genealogical database (around 290,000 people in 2004); consent is not involved as this uses existing public data. The database of genetic samples is gathered on the basis of informed consent. The Health Sector Database was enormously controversial because it presumed consent - that is, health data was to be gathered automatically, except from those who specifically opted out. ${ }^{17}$

- The resulting database is under exclusive licence to a commercial enterprise, deCode genetics.

These last two aspects have made the Icelandic database especially controversial, in that informed consent was to have been waived for health data collection, and that the research agenda is being shaped by a private company - which is, of course, hoping to profit from any findings. 
Almost as well-known is UK Biobank, a major initiative currently in its pilot stages. ${ }^{18}$ This is supported by the UK government, the Medical Research Council, and the Wellcome Trust (the world's largest medical research charity) at a projected cost of $£ 60$ million (and many suggest this will represent only the initial costs). It will gather samples and data from half-a-million people, aged 40-69 - most of whom will be healthy but many of whom will develop some of the major diseases of Western societies - heart disease, cancer and so on - in the next decades. Consent will be asked, and there will be no exclusive licence to a commercial enterprise, though private companies will have access to the biobank, on terms yet to be established.

Finally, I want to mention a third type of research biobank, smaller and better established than the large-scale adult databases just mentioned. Various child-cohort studies exist around the world. The UK has two important examples. In Bristol, there is the Avon Longitudinal Study of Parents and Children, ALSPAC, otherwise known as the 'Children of the 90s' study. This includes information about 14,000 children born in the early nineties, as well as their mothers and fathers. Biological samples, medical information and lifestyle information are gathered on a regular basis from all the children. By stark contrast with UK Biobank, this project has been funded on a shoe-string, by small, discontinuous grants from the various UK funding bodies. There is also the North Cumbria Community Genetics Project, which is more narrowly directed toward genetic studies, with samples from about 5,000 children and their mothers.

The scale of the Iceland database and UK Biobank can only partly explain the attention they have received. After all, the UK's National DNA Database is far larger than both combined, and much longer established; this is true of forensic biobanks in other countries too. ${ }^{19}$ The child cohort studies are also much better established, having been up and working for over a decade. I would like to suggest that the greater attention devoted to these new, largely speculative projects has arisen not only because of their scale but because they are more congenial to our framing assumptions about ethics. Although the large adult biobanks unquestionably pose difficulties for our established ethical framework for medical research, they are by no means as problematic as the forensic and child cohort cases, because informed consent remains an important and relevant issue. ${ }^{20}$ (So too confidentiality, but this is a concern for all my examples.) Nonetheless, consent serves us badly as a point of orientation for the adult medical banks, as well as being nigh-on useless in the child and forensic cases. The larger, better-established forensic databases can help us meet this difficulty, because in these cases it is self-evident that not consent but public policy principles (such as institutional oversight) and competing political priorities (eg, crime detection, limiting state surveillance) must provide the framework for our thinking. Here we can no longer maintain artificial divides between the ethical and the political, between individual rights and public goods

Why are individual rights, to consent or confidentiality, inadequate to the new largescale research biobanks, like Iceland's or UK Biobank? I suggest the answer is relatively straightforward. They transcend our usual examples of medical research in three important respects: (1) These projects are prospective and open-ended by their very nature, and necessarily are very broad and indeterminate in their research purposes; (2) Most of the research subjects will not be ill; in many respects, moreover, 
it would be better to begin with children rather than adults; (3) Their sheer scale means that they evade our standard mechanism for ensuring that individuals participate in well-designed research, the research ethics committee. I will comment on the first and second points in turn; the question of how well-conceived the research biobanks arises as an important issue for both.

With regard to the prospective nature of the studies: The biobanks require an on-going contribution from the research subject. If not samples, then at least health information and possibly lifestyle data should be entered into the bank over an indefinite period of time - ideally, until death, or, rather, post-mortem. This has, in turn, two important implications. First, complete anonymisation of data is impossible, as this would prevent new data being linked to the old, and to the tissue sample or genetic information. The best we can do is to code data, and entrust linkages to a secure bureau or trustee. (As the forensic databases remind us, genetic information is in principle never securely anonymous.) This means that there are always risks to subjects in terms of breaches of confidentiality, and there are many interested parties such as insurance companies, employers and even state agencies who might use such information against subjects' interests. Of course, these risks are likely to increase over time, to the extent that we become better able to interpret individual genetic variations.

Second, and more important from the point of view of consent: it is necessarily impossible to inform research subjects about the nature of the research that will be conducted with the biobank. As our knowledge increases, we can hope to investigate much more with the information banked, but what that 'much more' will be no one can say. However - and this point is by no means incidental - this is not just a problem of inevitable ignorance on the part of scientists and subjects. (After all, there will always be ignorance about the future outcome of any meaningful research study.) It also relates to an on-going problem of overstatement regarding the projected uses and findings of the biobanks. We are being promised all sorts of knowledge and benefits, yet these promises are often vaguely articulated and, on examination, frankly implausible.

This implausibility begins with the major practical issue for any study of such a scale: how to obtain and process sufficiently detailed and accurate information concerning the lives, health and changes in physical condition of the research subjects. Though some lifestyle and environmental factors, such as smoking, are fairly easy to record, others, such as diet, alcohol intake and physical activity are more complex and problematic (self-reporting is notoriously unreliable), so too psychosocial variables. Similarly, medical information is extremely difficult to gather and codify except in categories that will often be too wide for meaningful comparison. Measurements of simple physical variables such as blood pressure need to be repeated if research subjects are to be compared informatively, while repeated measurements of more complex variables - anything from glucose levels to cholesterol to blood cell counts will be extremely costly on such a scale. Thus greater understanding of the connections between genetic variations and disease susceptibility is only likely to arrive in the most crude and unhelpful forms. Smokers with these genetics variants and a diet including meat (Which meats? Eaten how often? And with what?) have on average - an $x \%$ higher risk of heart disease. 
At least some of these issues can be overcome with sufficient resources. Behind them, however, stands the well-known yet neglected fact that the diseases most often mentioned in connection with the medical biobanks are diseases of Western societies - that is, diseases whose causation can only have a slight basis in genetic variations, and are overwhelmingly related to socio-economic, environmental and lifestyle factors. $^{21}$

These obvious scientific difficulties have not discouraged highly speculative suggestions about the findings and technologies that might result from biobank research. Two in particular recur in the literature. We are promised pharmacogenomics - drugs 'tailored to each individual's genetic constitution' - and population genetic screening - the possibility of screening for susceptibility to various diseases, with the promise that preventative measures can then be tailored to individuals. Both seem unlikely to materialise and unlikely to generate significant benefits if they do. Consider population screening: we may find out that some individuals have a higher risk of some sort of heart disease should they fail to exercise regularly as compared to others. The obvious preventative measure is regular exercise - something which we should all undertake anyhow. More speculative measures include drugs that will have a prophylactic effect - 'pills for the healthy ill,' as they have been ironically christened - with the attendant costs of testing and the risks of any pharmaceutical intervention. None of this looks likely to represent good value for money from a public health perspective. ${ }^{22}$

So far as pharmacogenomics is concerned: there may be some basis for expecting some useful tests for some particular (classes of) drug, but the overall benefits are likely to be relatively slight. So far as the cost-benefit ratio of any test that does emerge is concerned, the issues here are twofold. First, most adverse drug reactions arise from dosage problems, interactions with other drugs or environmental factors, or physiological problems such as impaired liver or kidney function. Second, many problems of intolerance or non-response to drugs will therefore not be predicted by genetic tests, which in any case are likely to yield only probabilistic information, so that the need for careful monitoring of a patient's drug response will not be diminished. Both of these difficulties would apply even if it proved relatively straightforward to identify pertinent genetic variations and turn them into a cheap, reliable test. ${ }^{23}$

Clearly much more might be said with regard to these difficulties, but the broad problems with both sets of promises are easy to see. I mention them here for two reasons. First, as regards the 'informed' part of consent, they suggest that subjects are liable to be misled about the broad terms of the biobanks they join. ${ }^{24}$ Second, they point us to issues that go much beyond those individuals - above all, to the question of whether these projects are scientifically well-justified and reasonable value for money, as against the many other ways we might invest in health and health research. It is interesting, moreover, that the biobanks' ambitions are notably congenial to pharmaceutical companies (in terms of markets for genetic tests and prophylactic and remedial drugs), despite the fact that most large-scale medical biobanks are heavily reliant on public funding. It seems that a reductive, individualistic and medicalised approach to health is dominating our thinking about genetic research - despite the fact 
that this research is essentially collective in nature, despite the fact that genetics might just as well remind us how much human beings have in common and how greatly variations between people must be attributed to non-genetic factors.

To turn, now, to a second important respect in which large-scale medical biobanking differs from conventional medical research: Most of the participants will not be suffering any particular illness. This is advantageous from the point of view of consent, both so far as adult subjects and parents of child subjects are concerned: not experiencing the strain of illness and not needing to be grateful for present health care, people are more able to attend to the research proposal and less likely to feel pressured into participating. The disadvantage of this, however, is that research subjects are much less likely to take an active interest in the research being done that is, to feel responsible for ensuring research is done that reflects their interests. Over the past two decades, we have increasingly seen patient groups forming (albeit sometimes with the connivance of pharmaceutical companies), who have lobbied for research into their conditions: I have already mentioned the crucial role of patient activism, and more broadly gay activism, in HIV/AIDS research. We surely cannot expect participants in UK Biobank to take to the streets to ensure that this resource is used for the public interest; at most, there may be a tendency for subjects to withdraw their participation if it becomes clear that a biobank is not being used for ends they can endorse. $^{25}$

In addition to being mostly well, there is a case for thinking children would make more suitable subjects, so long as we want to give due weight to environmental factors. In particular, if we want to know about the explosion of allergies, asthma and food intolerances, or about conditions that promise premature death such as diabetes and obesity, then we need to know an awful lot about the details of childhood development, including development during pregnancy. ${ }^{26}$ As with the common causes of mortality mentioned in connection with the adult biobanks, these are obviously not disorders with a substantial genetic basis. Furthermore, the findings of such studies are unlikely to point to pharmaceutical interventions. Most probably such interventions will consist in broad public health measures, likely to be lower in risk, cheaper per person and more beneficial to everyone - apart, one is tempted to add, from those with an interest in selling more medical drugs or tests.

It is quite clear that informed consent is barely relevant to justifying child-cohort studies, and it is at least arguable that our preoccupation with consent has undermined them - making child research appear much more problematic than need be. (I have already mentioned how badly funded such projects have tended to be; the disparity in funding between these and UK Biobank is especially notable.) If such projects are to be justified, consent must of course play a role - to start with, parental consent, and later and increasingly, the children's consent. Here consent is operating not so much to protect children's interests, which must be an important duty on the part of those designing and managing the study, but rather to ensure trust and to promote fuller participation. (The sort of detailed information required about subjects cannot, after all, be discovered without the willing involvement of parent as well as child.) But beyond consent, and still more important, is scrutiny of the research undertaken using the data - whether it is well-conceived and likely to yield meaningful knowledge and benefits. The crucial question must be the soundness of the project in toto - whether it 
really brings together data of the detail and quality needed to investigate lifestyleenvironment-health interactions (with the possibility of investigating genetic factors where this seems likely to be fruitful), whether it is really likely to yield cost-effective measures to improve health.

It is useful, too, to remember the forensic databases, where genetic knowledge is being exploited for non-health purposes. Here, no one talks about consent, which would render the collections barely useful; samples are usually taken on a statutory basis. What has been important in justifying such databases is not individual rights but the public interest in detecting the culprits of violent crimes. Especially the association of DNA samples with sexual offences has made this justification overwhelmingly persuasive to the public. This does not mean that many critical points should not be made about forensic databases. ${ }^{27}$ Here we lack not only the limited protections afforded by consent procedures but also the other well-developed checks of medical and research ethics - above all concerning confidentiality, scrutiny of research proposals and institutional oversight. These databases represent a huge growth in potential state power. Costs (as benefits) to individuals can be very severe, and abuses or infringements of individual rights are easy to imagine. Here, again, one may fear that a seductive 'genetic fix' is at work: some worry that genetics is diverting attention from careful forensic work; in any case, such a database is hardly preventative of crime and its overwhelmingly social causes (although we might hope that the databases will develop some deterrent effects).

Nonetheless, there is widespread recognition that we should think about forensic databases in political terms such as the public interest, the extent of state power, and checks and balances such as (presently lacking) institutional oversight mechanisms to regulate access and usage. Much less is said about the forensic banks: this is partly because it is much more difficult to investigate their workings, and partly because they fall less than squarely within the conventional domain of bioethics. But I have also pointed to a less welcome explanation: might this neglect not also reflect the indubitable fact that they raise significant political questions - questions which expose the narrowness of 'ethics' as it is commonly understood? So long as we do pay attention to the forensic banks, however, we will have no doubt that large-scale biobanking raises important policy and political issues, issues which cannot be dealt with by focussing on individual rights. Not the least of these - as in the forensic case, as in the justification of studies on children who cannot meaningfully consent - will be whether the banks represent a worthwhile priority, liable to generate knowledge and benefits on a scale commensurate with the investment they demand. 


\section{Conclusion}

Most bioethical writing on biobanking recognises some of the limitations of a framework based on individual rights, and there have been repeated calls for other principles to frame the issues. Some candidates that have been offered include solidarity, altruism (the 'gift relationship'), benefit-sharing and 'governance.' These concepts have made some impact on public and policy discourse, but have often been taken up in a frankly instrumental way - 'gift' being a well-documented example, whereby subjects get moral credit and nothing else in return for their participation. ${ }^{28}$

The first part of my discussion argued that informed consent is an ideal whose practice has turned out to be more complicated and ambivalent than one would wish. This is no more than one might expect when an ideal is pulled into practice: situated amid competing interests and diverse institutional imperatives, deployed in contexts which were quite unthought of when it was originally coined. We might suspect that other general principles are liable to meet similar fates: a duty to participate in collective research, a notion of altruistic donation, the imperative for just sharing of benefits, and the importance of institutional regulatory mechanisms - these are all ideas with clear validity, but their limits are not difficult to see. Moreover, none of them really highlight the central questions that biobanks pose: How well-conceived is this line of research? What will its benefits be? Why this research and not something else? How are we organising and funding research? Nor do they help us uncover the presuppositions we may be making about the nature of health and ill-health: I have only alluded to a few of the problems involved in conceiving of health in individual, genetic, and medicalised terms. No one can believe that this is anything like the whole story about health, but as an unexamined assumption it is surely a powerful factor in keeping (bio)ethics away from political and economic factors.

Be that as it may, the more immediate motivation for my argument here has been the fear that the new large-scale medical biobanks will prove wrong-headed ventures, which will generate relatively little basic knowledge and few useful applications. Certainly, they seem unlikely to take us much closer to key sources of chronic illhealth, nor to generate population-wide measures that tackle common causes of premature death. We may end up thinking of UK Biobank as the Millennium Dome of British medical research, a glamorous white elephant, expensive but of little use. However much UK Biobank may not infringe individual rights, it has been too large to be caught by less commonly mentioned research safeguards such as scientific peer review. This assessment may be overly pessimistic. But I think my central argument will still stand: that 'ethics' must engage important questions about what is being researched and why, about our priorities for publicly funded research, about how research is organised and funded. Informed consent is much too close up for us, or research subjects, to see this question: its limitations should remind us of the huge power differentials between individual research subject and researching organisations. Likewise, the net of research ethics committees and scientific peer review is also too close to catch such issues, which concern the aggregate picture. Yet the worse reasons for the enduring popularity of informed consent may remind us that there are powerful factors at work in keeping 'ethics' away from these questions. 
* A version of this paper was originally presented as part of a British Council Sino-UK Bioethics Workshop "Ethics and Life Sciences" in Beijing, 19-20 October 2004, and at related lectures in Chongqing. My thanks to the British Council for this invitation, and to colleagues at Lancaster University for their comments on drafts of this paper, especially Dave Archard, Georg Bosshard, Ruth Chadwick, Mairi Levitt, Heather Walmsley and Sue Weldon. My thanks, too, to the referees of this journal.

1 Summarised usefully by B. Knoppers and R. Chadwick. Human genetic research: emerging trends in ethics. Nature Reviews: Genetics 2005; 6: 75-79.

2 In making this case, I shall most be concerned with Anglo-American discussions of these questions. Some may wish to argue that other Western countries, having different legal and philosophical backgrounds, tend to frame the issues differently. However, European statements on biobanking also tend to focus very narrowly on individual rights. See: Nationaler Ethikrat [German National Ethics Advisory Board]. 2004. Biobanken für die Forschung: Stellungnahme [Statement on research biobanks]. Berlin. Nationaler Ethikrat; Comité Consultatif National d'Éthique [National Consultative Bioethics Committee]. 2003. Ethical issues raised by collections of biological material and associated information data: "biobanks," "biolibraries". Paris; and European Society of Human Genetics. [Recommendations on] Data Storage and DNA Banking for Biomedical Research: Technical, Social and Ethical Issues. European Journal of Human Genetics 2003; 11: 8-10.

3 For similar criticisms see: Ted Schrecker. 2003. Benefit-Sharing in the New Genomic Marketplace: Expanding the Ethical Frame of Reference. In Populations and Genetics: Legal and Socio-Ethical Perspectives. Bartha Knoppers, ed. Martinus Nijhoff. Leiden: 405-411; and Chris MacDonald. 2003. Patents and Benefit-Sharing as a Challenge for Corporate Ethics. Also in Knoppers, op cit: 505-523.

4 Contrast Anne Kerr's argument, using the examples of gene patenting and stem cell research: Governing genetics: reifying choice and progress. New Genetics and Society 2003; 22: 111-126.

5 See also O. O'Neill. Informed consent and public health. Philosophical Transactions of the Royal Society: Biological Sciences 2004. 359: 1133-1136.

6 Another difficulty is whether the choice offered is Hobson's choice, that is, not a real choice for subjects at all: an issue for those with serious conditions who have few options left for treatment. An interesting issue, just coming into sight, is the question of what information should be provided to subjects about the progress and interim findings of their studies.

7 Different problems arise with regard to the position of criminals and soldiers, who (are judged to) have forfeited certain rights. While there has been widespread recognition that trials should not be conducted on prisoners, the position of soldiers has remained deeply problematic.

8 This is not to deny that statistical methods will sometimes be able to compensate for incomplete samples or bias in selection, depending on the investigators' purpose, situation and possession of relevant background knowledge.

9 See: E. Haimes and M. Whong-Barr. 2004. Levels and Styles of Participation in Genetic Databases: A Case Study of the North Cumbria Genetics Project. In Genetic Databases: Socio-ethical issues in the Collection and Use of DNA. O. Corrigan and R. Tutton, eds. London. Routledge: 57-77; H. Busby. 2004. Blood donation for genetic research: what can we learn from donors' narratives? In Corrigan and Tutton, op. cit: $39-56$.

10 N. Rose. 1999. Powers of Freedom: Reframing Political Thought. Cambridge. Cambridge University Press: 87; quoted in A. Petersen and R. Bunton. 2002. The New Genetics and the Public's Health. London. Routledge: 183.

${ }^{11}$ Cf A. Petersen and R. Bunton, op cit: 193f, who highlight the prominence of 'freedom of choice' and 'informed consent' in many support groups' aims and discourse.

${ }^{12}$ This is to leave aside the argument that there is nonetheless a certain loading of the issues in making 'information' available via such counselling, leading some disability rights writers to refer to present practice as 'weak eugenics': thus T. Shakespeare. Eugenics, Genetics and Disability Equality. Disability and Society 1998; 5: 665-681, 669.

13 G. Annas. Reforming informed consent for genetic research. JAMA 2001; 286: 2326-2328; G. Porter. 2004. The wolf in sheep's clothing: informed consent forms as commercial contracts. In G. Árnason, S. Nordal \& V. Árnason, eds. Blood and data: ethical, legal and social aspects of human genetic databases. Reykjavik. University of Iceland Press: 85-93.

14 B. Hofman. 2004. Do biobanks promote paternalism? On the loss of autonomy in the quest for individual independence. In Árnason et al, eds, op cit: 237-242, 241. 
15 On technocracy, see S. Weldon. 'Public Consent' or 'Scientific Citizenship'? What Counts as Public Participation in Population Based DNA Collections? In Corrigan and Tutton, op cit (n. 9): 172. Particularly notable in our context is the regulatory framework for UK Biobank, where the Ethics and Governance Council and Science Committee form two quite separate entities, with different forms of 'expertise' being deemed appropriate to each.

16 NDNAD's Fact Sheet of March 2005 claims 'NDNAD now holds around 2.9 million DNA profiles from individuals and 237,500 profiles from crime scenes' (at www.forensic.gov.uk).

17 As an aside, it may be worth noting that this opt-out provision would undermine the statutory health care research that the health sector database would also have been used for. An opt-out rate of around $10 \%$ was expected, one that would probably be much greater in specific sub-groups such as the mentally ill. Thus research on the functioning of the health service as a whole would be compromised by introducing this malnourished cousin of informed consent.

${ }^{18}$ See www.ukbiobank.ac.uk. For a more detailed critique of the project, see A. Petersen. Securing our genetic health: engendering trust in UK Biobank. Sociology of Health \& Illness 2005; 27: 271- 292.

19 For an early alarm call on the US situation, see Pamela Sankar. The Proliferation and Risks of Government DNA Databases. American Journal of Public Health 1997; 87, 336-337.

20 There are many discussions of the limitations of, and possible modifications that might be made to, informed consent procedures here. See inter alia: G. Annas. Reforming informed consent for genetic research. JAMA 2001. 286: 2326-2328; T. Caulfield, E.G.U. Ross and A. Daar. DNA databanks and consent: a suggested policy option involving an authorisation model. BMC Medical Ethics 2003. 4; D. Schroeder and G. Williams. Human genetic banking: altruism, benefit and consent. New Genetics and Society 2004. 23: 89-103

21 It might still be argued that knowledge of the (many) relevant genes might improve our understanding of the pathways of such diseases. Yet the sheer statistical difficulty of tracking multiple gene associations should caution us against this claim.

${ }_{22}$ See P. Vineis, P. Schulte and A. McMichael. Misconceptions about the use of genetic tests in populations. Lancet 2001; 357: 709-12; GeneWatch. 2002. Genetics and predictive medicine: selling pills, ignoring causes. Briefing paper 18; GeneWatch. 2004. Bar-coding babies: good for health? Briefing paper 27. Both at www.genewatch.org.

${ }^{23}$ For overview and references, see GeneWatch. 2003. Pharmacogenomics: Better, safer medicines? Briefing paper 23, as well as their 2001 paper: Human bio-collections: who benefits from gene banking?. Briefing paper 14. Both at www.genewatch.org.

${ }^{24}$ UK Biobank's website promises that the project will 'improve our understanding of the biology of disease and develop improved diagnostic tools, prevention strategies and tailor made treatments for disorders that appear in later life' (www.ukbiobank.ac.uk).

25 There may be some basis for optimism here. Some have suggested that the prospective and collective nature of biobanks might allow us to think of them, not like conventional research projects where control must reside with the researcher, but rather on the model of 'subscription clubs,' where subjects retain an on-going stake in the project. It is difficult to see how this might work in practice (and there is little sign that UK Biobank is thinking in these terms) but we can certainly conceive of mechanisms that would permit subjects to be not just informed about, but involved or represented in, establishing the uses made of the biobank.

26 Likewise, if we want to understand the glaring relation between health and socio-economic class patently far more important to variations in health than genetic make-up - then we need to be tracking health and physical development against environment, nutrition, familial background, and so on.

27 See: GeneWatch. 2005. The Police National DNA Database: human rights and privacy. Briefing paper 31. At www.genewatch.org; R. Williams, P. Johnson and P. Martin. 2004. Genetic Information and Crime Investigation. At www.dur.ac.uk/p.j.johnson.

28 R. Tutton. 2004. Person, property and gift: exploring languages of tissue donation to biomedical research. In Corrigan and Tutton, op cit (n. 9): 19-38. 